\title{
Polymer Electrolyte Water Electrolysis: Correlating Performance and Porous Transport Layer Structure: Part II. Electrochemical Performance Analysis
}

\author{
Tobias Schuler, ${ }^{1}{ }^{1}$ Thomas J. Schmidt, ${ }^{1,2, *}$ and Felix N. Büchi ${ }^{1,2}$ \\ ${ }^{1}$ Electrochemistry Laboratory, Paul Scherrer Institut, CH-5232 Villigen PSI, Switzerland \\ ${ }^{2}$ Laboratory of Physical Chemistry, ETH Zürich, CH-8093 Zürich, Switzerland
}

\begin{abstract}
In the first paper of this series the bulk and surface structural properties of Ti-fiber based porous transport layers (PTL) were characterized and described. In this second part the correlation of structure to the performance in polymer electrolyte water electrolysis cells is analyzed by determination of the three main overpotentials of ohmic, kinetics and mass transport losses. The strongest correlation between the PTL bulk transport properties and cell performance is obtained for heat transport. The current density dependent temperature gradients show good agreement with ex situ determined heat conductivity from part one. However, surface properties of the PTL materials, have a stronger influence on cell performance than the bulk properties. Catalyst layer utilization and ohmic interfacial resistances correlate with the interfacial contact areas reported in part one and performance increases with increasing contact area. This is due to a local mass transport resistance decreasing with increasing catalyst layer utilization.

(C) The Author(s) 2019. Published by ECS. This is an open access article distributed under the terms of the Creative Commons Attribution Non-Commercial No Derivatives 4.0 License (CC BY-NC-ND, http://creativecommons.org/licenses/by-nc-nd/4.0/), which permits non-commercial reuse, distribution, and reproduction in any medium, provided the original work is not changed in any way and is properly cited. For permission for commercial reuse, please email: oa @ electrochem.org. [DOI: 10.1149/2.1241908jes]
\end{abstract}

(cc) BY-NC-ND

Manuscript submitted March 5, 2019; revised manuscript received May 3, 2019. Published May 24, 2019.

Operational cost (OPEX), primarily power consumption, is the one of the main cost drivers for hydrogen produced with polymer electrolyte water electrolysis (PEWE) technology., Roughly $70 \%{ }^{3}$ of the hydrogen production cost stems from electricity. Overall process efficiency has therefore a direct influence on the electrolysis OPEX. ${ }^{4,5}$ The governing parameters for efficiency in PEWE cells are the kinetic, electric and mass transport overpotentials. While at low current densities the kinetic overpotential is responsible for the highest losses, at high current densities typically ohmic losses represent the largest fraction. However at high current densities, also mass transport plays an important role with respect to efficiency losses, in particular when thin membranes ${ }^{6,7}$ are used. The structural properties of the porous transport layers (PTL) affect all three main loss categories.

The ohmic resistance of a cell is primarily governed by the membrane thickness, as the specific resistivities of different types do not show large variations. However, as observed by different research groups $^{8-11}$ also the PTL type has an influence on ohmic resistance. This does not stem from the electric through-plane conductivities (throughplane is the across the thickness of the PTL direction), which are in the range of $10^{6} \mathrm{~S} / \mathrm{cm}^{8,12}$ and therefore provide a negligible ohmic contribution at thicknesses in the range of a millimeter. Ohmic resistance may occur from surface oxidation, therefore Bystron et al. ${ }^{13}$ etched Ti felt based PTLs which resulted in a significant resistance reduction, attributed to lower surface $\mathrm{TiO}_{2}$ layer thicknesses. A resistance decrease was also reported by Lettenmeier et al. ${ }^{9}$ for modifying a commercially available Sika GKN T10 transport layers by vacuum plasma spray coating,,${ }^{9,14}$ generating an additional Ti-layer on top of the coarse structures of the Ti powder sintered material. The origin of the improvement is unclear, whether it is mainly due to a decrease in surface resistance or a geometric effect.

A study by Mo et al. ${ }^{15}$ showed only a partial utilization of the catalyst layer, with the oxygen evolution reaction primarily observed at the three-phase boundaries of porous transport layer, catalyst layer and liquid water. The geometry of the interface between PTL and catalyst appears to have an essential influence on catalyst utilization. When electric in-plane conductivity in the catalyst layer would be the limiting parameter, as postulated, ${ }^{16}$ kinetic activation losses should scale inversely with catalyst layer utilization. Vacuum plasma spraying of PTLs ${ }^{9}$ leads to an increase of surface area and promotes a decrease of ohmic resistances but at the same time no improvement in kinetics

\footnotetext{
*Electrochemical Society Member.
}

${ }^{\mathrm{z}}$ E-mail: felix.buechi@psi.ch in comparison to the untreated PTLs was observed. ${ }^{9}$ Kang et al. ${ }^{17}$ conducted measurements with thin perforated titanium sheets coated with Ti particles. Lower kinetic activation losses but higher ohmic resistances were measured. Controversial trends are reported and the correlation between PTL surface modifications and kinetics as well as underlying processes are not identified. The understanding of PTL surface structure and contact area between PTL and catalyst layer and its relation to ohmic and kinetic losses therefore remains an essential gap in literature.

The least understood loss category is the mass transport losses. Several studies focused on its dependence on the PTL bulk structure. Investigating the pressure and temperature dependence, Suermann et al. ${ }^{8}$ performed measurements with Ti-powder sintered PTL, at pressures up to 100 bar observing a decrease of the transport overpotential with increasing gas pressure. Influence of PTL bulk properties on PEWE performance was also reported by Grigoriev et al. ${ }^{18}$ Their study focused on the characteristics of spherical Ti-particles sintered PTLs. They proposed an optimal pore diameter in the range of $12-13 \mu \mathrm{m}$ for spheres in the range of $50-75 \mu \mathrm{m} .{ }^{18}$ Ito et al. conducted measurements based on Ti-fiber meshes and in accordance with Grigoriev et al. ${ }^{18}$ the results of the electrochemical characterization implied an optimum pore diameter larger than $10 \mu \mathrm{m}$. However, neither the influence of structure of PTLs nor the geometry of the interface to the catalyst layer on mass transport losses is understood at the time and also represents an essential gap in literature so far.

The present study focuses on a better general understanding of the correlation between PTL bulk and surface properties and the electrochemical performance. Therefore a systematic PTL matrix of six materials with three fiber diameters and two porosities is characterized. Electrochemical performance is analyzed in detail for the three main overpotentials and correlated to the PTL bulk and surface properties, reported in Part $\mathrm{I}^{19}$ of this series of papers.

\section{Experimental}

Materials.-A matrix of six PTL materials based on titanium fibers (NV Bekaert SA, Belgium) with two nominal porosities of $56 \%(\mathrm{~L}), 76 \%(\mathrm{H})$ and three nominal fiber diameters of 14, 20 and $50 \mu \mathrm{m}$ is used and compared to the state of the art particle sintered material SIKA T10 (GKN Sinter Metals Filters GmbH, Germany). The fiber materials are labeled L1 (low porosity, smallest fiber) to H3 (high porosity, largest fiber). In Part ${ }^{19}$ a detailed characterization of the bulk and topology properties of the materials was reported 
(Tables I and II in Part I). ${ }^{19}$ Before cell assembly, the PTL samples were cleaned by ultra-sonication in a $20 \mathrm{wt} \%$ acetone solution twice for $15 \mathrm{~min}$ and subsequently for $15 \mathrm{~min}$ in DI water. Commercially available CCMs, Greenerity E400 (Greenerity, Germany) were used. These CCMs are based on Nafion N117 CS membranes (dry membrane thickness $175 \mu \mathrm{m}$ ).

$\boldsymbol{P E W E}$ cell.-An in-house developed cell with an active area of $4 \mathrm{~cm}^{2}$ described in Suermann et al. ${ }^{20}$ was used for electrochemical characterization. The differential cell allows for investigation of fundamental processes due to the absence of significant along the channel effects of temperature and other relevant parameters. A spring design allows for a controlled contact pressure of $2.5 \mathrm{MPa}$ in the active area, independent of PTL thickness variation. The flow fields of anode and cathode have 5 parallel channels with a length of $20 \mathrm{~mm}$, width of $2 \mathrm{~mm}$ and depth of $1 \mathrm{~mm}$, separated by $2 \mathrm{~mm}$ wide ribs. All parts being contact in DI-water are gold coated. PTFE and PTFE coated fiber glass subgaskets were used for electric insulation and gas tightness. The cell temperature is measured by a thermocouple situated in a drilled hole close to the active area.

Testbench and periphery.-The test-bench is described in detail in Ref. 20. It has two separate gas/water loops. DI water is recirculated with a volume flow of $30 \mathrm{ml} \mathrm{min} \mathrm{m}^{-1} \mathrm{~cm}^{-2}$ on the anode side, the cathode side recirculation is driven by natural convection. An ion exchanger is integrated in the anodic feed DI-water loop to sustain high DI water purity during testing. The cell temperature is controlled by heating of the fluid streams before entering the cell. For the electrochemical measurements a Biologic VSP-300 (Bio-Logic SAS, France) potentiostat was used, allowing for simultaneous high frequency resistance (HFR) measurements.

Electrochemical measurements. - The cells were conditioned for at least $10 \mathrm{~h}$ at a pressure of 3 bar in $\mathrm{N}_{2}(\mathrm{~g}) / \mathrm{H}_{2} \mathrm{O}(\mathrm{l})$ configuration before the break-in cycle protocol $\left(2.0 \mathrm{~V}-2.6 \mathrm{~V}, 50^{\circ} \mathrm{C}\right)$. Measurements were started when performance and HFR reached stable conditions with $\triangle \mathrm{HFR}<0.001 \Omega \mathrm{cm}^{2} / \mathrm{min}$. A current density of $2 \mathrm{~A} / \mathrm{cm}^{2}$ was applied as reference condition before performing polarization curves. Current densities in the range of 0.001 to $0.4 \mathrm{~A} / \mathrm{cm}^{2}$ were recorded in galvanostatic mode. Suermann et al. ${ }^{7}$ have shown that a holding time of $10 \mathrm{~s}$ at each current density is a useful compromise between thermal equilibrium and safety due to gas crossover at low current densities and elevated pressures. The high frequency resistance was measured at every current density step at $25 \mathrm{kHz}$ for $1 \mathrm{~s}$ as suggested by Suermann et al. ${ }^{7}$ A single measurement series was conducted for all samples, except for materials L1 and L2 where the reproducibility was checked with two independent cell builds. Polarization curves were repeated three times for each PTL and cell build at 10 bar and $50^{\circ} \mathrm{C}$.

\section{Theoretical Background}

Overpotential analysis. - The cell voltage $\mathrm{E}_{\text {cell }}$ is composed of the sum of the reversible cell potential $\mathrm{E}^{0}(\mathrm{p}, \mathrm{T})$ and the three main overpotentials $\eta_{\mathrm{i}}$ :

$$
E_{\text {cell }}=E^{0}(p, T)+\eta_{k i n}+\eta_{\Omega}+\eta_{m t x}
$$

where $\eta_{\text {kin }}$ is the kinetic, $\eta_{\Omega}$ the ohmic and $\eta_{\mathrm{mtx}}$ the mass transport overpotential. Mass transport comprises the effects of the fluid transport in the PTL/CL and the ionic transport in the catalyst layers.

Equilibrium cell voltage $\boldsymbol{E}^{\mathbf{0}}$.-The equilibrium cell voltage $\mathrm{E}^{0}(p, T)$ for PEWE is described by the Nernst equation according to Eq. 2: It is a function of temperature $T$ and activity of the species $a_{i}$, where the activities are given by the partial pressures of the gases corrected for water saturation pressure. The activity of water is assumed to be unity:

$$
E^{0}(p, T)=E^{0}+\frac{2.303 R T}{2 F} \cdot \log \left[\frac{\left(a_{O_{2}}\right)^{1 / 2}\left(a_{H_{2}}\right)}{a_{\mathrm{H}_{2} \mathrm{O}}}\right]
$$

Ohmic overpotential $\eta_{\Omega}$.-Electrochemical impedance spectroscopy (EIS) is used to determine the high frequency resistance $H F R$ representing the total electric cell resistance $\mathrm{R}_{\mathrm{tot}}$. The ohmic overpotential $\eta_{\boldsymbol{\Omega}}$ is therefore given as:

$$
\eta_{\Omega}=j * R_{t o t}(T)=j * H F R(T)
$$

The $H F R$ is considered as a sum of sub-resistances, comprising the set up resistance $R_{\text {set up }}$, the ionic membrane resistance $R_{\text {mem }}$ and an interfacial ohmic resistance between PTL and catalyst layer $R_{\text {int }}$, observed in literature by several research groups. ${ }^{8-10,18}$ The electric bulk resistances of the $1 \mathrm{~mm}$ Ti PTLs are small $\left(10^{-6} \Omega \mathrm{cm},{ }^{28,12}\right.$ compare Part I $)^{19}$ and were therefore neglected. The interfacial resistance is considered an ohmic resistance at the interface of PTL and catalyst layer as well as PTL and bipolar plate. Pure ohmic resistances, based on metals and alloys have a slight, linear temperature dependence with a temperature coefficient in the range of $10^{-3}{ }^{\circ} \mathrm{C}^{-1} \cdot{ }^{21}$ The temperature effect can therefore be neglected. In contrast, the ionic conductivity of the membrane has a strong temperature dependence, ${ }^{22}$ which needs to be considered:

$\operatorname{HFR}\left(\bar{T}_{\text {mem }}\right)=R_{\text {set up }}+R_{\text {int }}+R_{\text {mem }}\left(\bar{T}_{\text {mem }}\right)=R_{\text {set up }}+R_{\text {int }}+\frac{t_{\text {mem }}}{\kappa\left(\bar{T}_{\text {mem }}\right)}$

where $\kappa\left(\bar{T}_{m e m}\right)$ represents ionic membrane conductivity, $t_{m e m}$ the swollen membrane thickness at operating conditions and $\bar{T}_{m e m}$ the average membrane temperature.

Kinetic overpotential $\eta_{\text {kin }}$ - - In the Tafel model, the Tafel slope $b$ and apparent exchange current density $j_{0}$ are the governing kinetic parameters. For determining these parameters the cell voltage $E_{\text {cell }}$ has to be corrected by the equilibrium cell voltage at operating conditions $E^{0}(p, T)$ and the ohmic overpotential:

$$
\eta_{k i n}=E_{c e l l}-E^{0}(p, T)-\eta_{\Omega}
$$

the kinetic ovepotential is related to the number of transferred electrons $n$, the applied current density $j$ and the exchange current density $j_{0}$. Assuming a non-polarizable hydrogen evolution reaction (HER) electrode, the entire kinetic overpotential is given by the oxygen evolution reaction (OER) with the Tafel slope $b$ defined as $2.303 R T / n F$ :

$$
\eta_{k i n}=b \log \frac{j}{j_{0}}
$$

Mass transport overpotential $\eta_{m t x}$. - The residual overpotential is attributed to mass transport associated to fluid transport in the catalyst layers (primary, secondary pores and ionomer thin film) $\eta_{\Pi, C L}$, the PTL bulk $\eta_{\Pi, P T L}$ and the ionic transport in the catalyst layers $\eta_{\sigma, C L}$ as:

$$
\eta_{m t x}=\eta_{\sigma, C L}+\eta_{\Pi, C L}+\eta_{\Pi, P T L}
$$

The origin of $\eta_{m t x}$, as well as the governing loss term are not well understood. In PEWE literature $\eta_{\text {mtx }}$ is generally related to geometrically normalized parameters, implying a $100 \%$ utilization of the catalyst layer. However, if the catalyst utilization depends on PTL interface structure, this will be reflected in the observed apparent exchange current density $j_{0}$.

For comparing the catalyst utilization of two different cells at constant kinetic overpotential, the ratio of the two current densities $j_{1} / j_{2}$ equals the ratio of their apparent exchange current densities. This ratio can be expressed as the relative catalyst utilization factor $X$ :

$$
X=\frac{j_{1}}{j_{2}}=\frac{j_{0,1}}{j_{0,2}}=\frac{\chi_{1}}{\chi_{2}}
$$

where $\chi_{i}$ are the catalyst utilizations of cells 1 and 2 . This becomes clear from Eq. 9 with the definition of the apparent exchange current density:

$$
j_{o, i}=j_{0}^{*} * x_{i} * r f *\left(a_{H_{2}} O\right)^{\kappa} * e^{\frac{-\Delta E_{a}}{R T}}
$$

where $\chi_{i}$ is the utilization factor of the catalyst layer $i$. All other parameters in Eq. 9 are the same for the two cells due to identical intrinsic 
catalyst properties such as the specific exchange current density $j_{0}^{*}$, the reaction order $\kappa$, the activation energy $\Delta E_{a}$, roughness factor $r f$ as well as constant operational parameters as temperature $T$ and water activity $a_{\mathrm{H}_{2} \mathrm{O}}$.

Suermann et al. showed a linear increase of mass transport overpotential with current densities for isothermal conditions. ${ }^{8}$ The total mass transport resistance comprises two transport resistances in series: the catalyst layer resistance $R_{c l}$, given by the ionic and fluid transport and the PTL resistance $R_{P T L}$ whose origin is the fluid transport in the PTL bulk.

It is known form polymer electrolyte fuel cells (PEFC) that catalyst layer mass transport resistances show a proportional relation to the inverse roughness factor $r f$, given as the product of catalyst loading $1_{\mathrm{IrO}_{2}}$ and electrochemically active surface area ECSA, the so-called local mass transport resistance $R_{m t x}^{\text {local }} .^{23,24}$ In contrary to PEFC, the determination of $r f$ is not directly accessible for PEWE, as the determination of the electrochemically active surface area (ECSA) by analysis of underpotentially deposited hydrogen on the typically used $\mathrm{Pt} / \mathrm{C}$ catalysts does not work for $\mathrm{IrO}_{2}$. The method proposed by Alia et al. ${ }^{25}$ was not considered because it requires disassembling of the cell and leads to loss of consistency. Therefore, it is proposed to use the relative utilization factor $X$, according to Eq. 8, as adequate parameter for correlation with catalyst utilization.

In this study a normalized catalyst layer mass transport resistance, capturing ionic and fluid transport induced transport in the catalyst layer, is introduced which is defined as:

$$
R_{C L}^{X}=\frac{d R_{C L}}{d X^{-1}} .
$$

The total mass transport resistance can then be finally described as:

$$
R_{m t x}=\frac{d \eta_{m t x}}{d j}=\frac{d \eta_{\sigma, C L}+\eta_{\Pi, C L}+\eta_{\Pi, P T L}}{d j}=R_{c l}^{X} \frac{1}{X}+R_{P T L}
$$

Thermal analysis.-Changes in average membrane temperature $\overline{\mathrm{T}}_{\text {mem }}(\mathrm{j})$ as function of the current density can be monitored directly by measuring the membrane resistance $R_{m e m}$, which is the dominant part of the HFR.

The temperature dependent proton conductivity for Nafion membranes N117 immersed in liquid water, proposed by Kopitzke et al., ${ }^{26}$ was used for the determination of the average temperature of the membrane. This data is in line with the results of Zawodzinski et al. ${ }^{27}$ From Eqs. 12, then $\kappa_{0}$ is determined to be $2.29 \mathrm{~S} / \mathrm{cm}$ and $\mathrm{E}_{\mathrm{k}}$ to be $7.83 \mathrm{~kJ} / \mathrm{mol}^{22}$

$$
\kappa\left(\bar{T}_{m e m}\right)=\kappa_{0} * e^{\frac{-E_{\kappa}}{R \bar{T} m e m}}
$$

When correcting for the temperature independent sub-resistances of set up and PTL/CL interface, the average membrane temperature $\bar{T}_{m e m}(j)$ can be determined by combining Eqs. 4 and 12 from the measured $H F R$

The increase of membrane temperature with current density is a function of the heat transport in the porous transport layers. The effective thermal conductivity $\sigma_{e f f}$ of PTLs can be determined from experimental data. A simplistic and idealized 1D-cell geometry, visualized in Figure 1, is used for this determination. Thermal boundary conditions of $\bar{T}(j)$ at the interface of between PTL and flow field are assumed to be constant. $\bar{T}_{m e m}(j)$ is then determined from the average homogeneous membrane temperature $\bar{T}_{m e m}(j)$ and linear temperature profiles between membrane and the PTL/FF interface. $\bar{T}_{m e m}\left(0 \mathrm{~A} / \mathrm{cm}^{2}\right)$ is defined as reference temperature for dynamic temperature increase of the membrane.

Finally the effective thermal conductivity for the PTLs $\sigma_{e f f}$ is calculated according to Eq. 13 using the thermoneutral cell voltage $E_{t n}$, the total PTL thickness $t_{P T L}$ and the temperature difference between arithmetic mean temperature at PTL/CL interface $\bar{T}$ and membrane temperature $\bar{T}_{m e m}$ :

$$
\sigma_{e f f}=\frac{\partial \dot{q} t_{P T L}}{\partial \Delta T}=\frac{\partial j\left(E_{c e l l}-E_{t n}\right) t_{P T L}}{\partial\left(\bar{T}_{m e m}-\bar{T}\right)}
$$
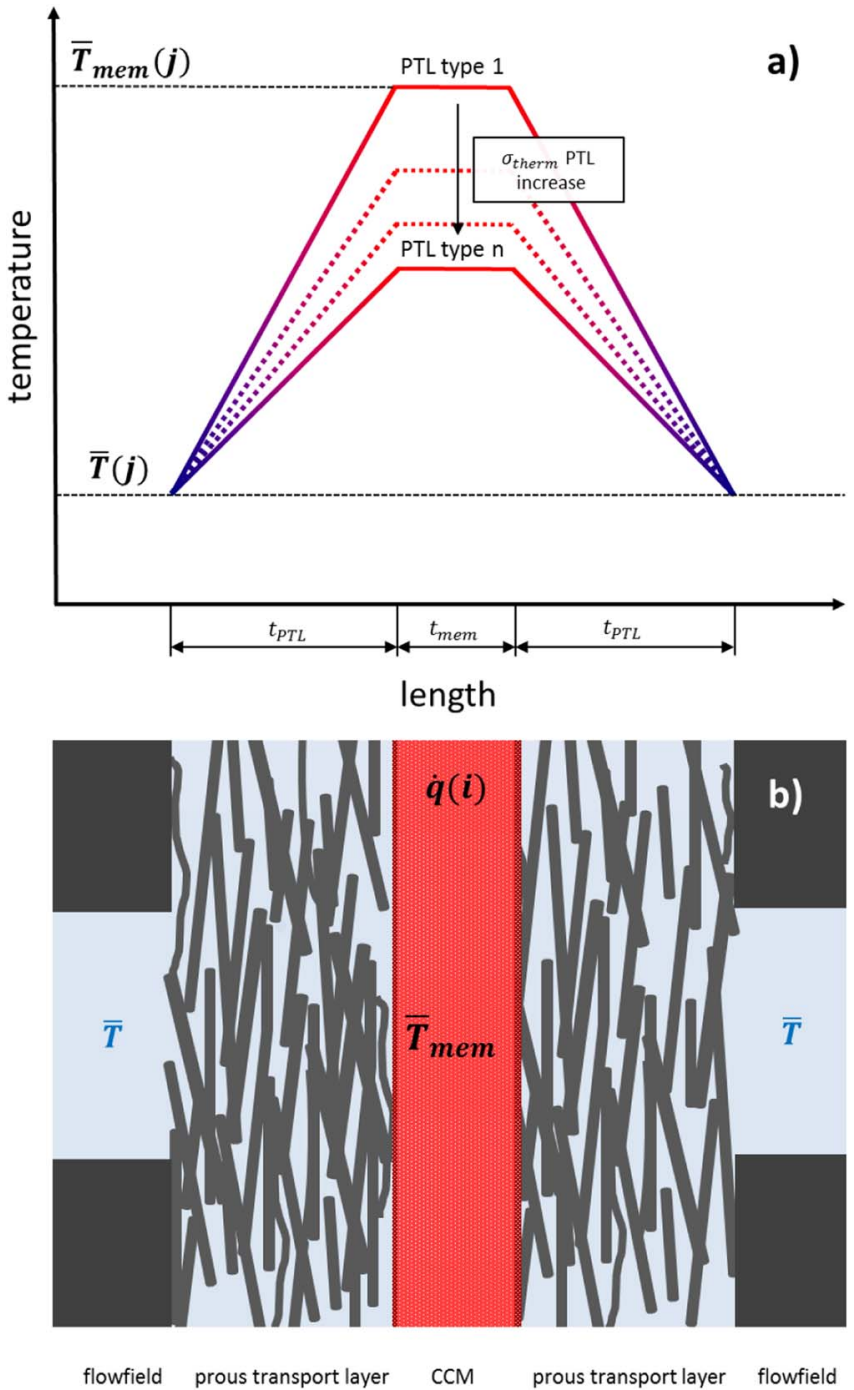

Figure 1. a) Schematic cross-section of CCM with porous transport layers; b) resulting temperature profiles and boundary conditions used for the calculation of the effective thermal conductivity $\sigma_{e f f}$.

where the thermoneutral cell voltage $E_{t n}$ is determined according to Eq. 14 with $\Delta H_{R}$ the reaction enthalpy and the arithmetic mean temperature $\bar{T}$ at PTL/CL interface is calculated according to Eq. 15:

$$
E_{t n}=\frac{\Delta H_{R}(T)}{n F}=\frac{\Delta H_{R}^{0}+\Delta_{R} c_{p}^{0}\left(T-T_{0}\right)}{n F}
$$

and

$$
\bar{T}(j)=\frac{j\left(E_{\text {cell }}-E_{\text {tn }}\right)}{0.5 c_{p, \mathrm{H}_{2} \mathrm{O}} \dot{m}_{\mathrm{H}_{2} \mathrm{O}}}+T_{\text {in }}
$$

with the standard reaction enthalpy of liquid water of $285.8 \mathrm{~kJ} /(\mathrm{mol} \mathrm{K})$ is corrected for a given temperature by the standard specific reaction heat capacity $\Delta_{R} c_{p}^{0}$ of $31.8 \mathrm{~J} /(\mathrm{mol} \mathrm{K})$ and the heat capacity of water $c_{p, \mathrm{H}_{2} \mathrm{O}}$ is given to be $4.2 \mathrm{~J} /(\mathrm{g} \mathrm{K}) .^{28}$

\section{Results}

The aim of this study is to elucidate the influence of the surface and bulk structures of the porous transport layer on PEWE performance by detailed analysis of the overpotentials. The electrochemical performance is then related to the bulk transport and surface properties of the materials, which have been obtained from X-ray tomographic microscopy (XTM) in Part $\mathrm{I}^{19}$ of this study. 

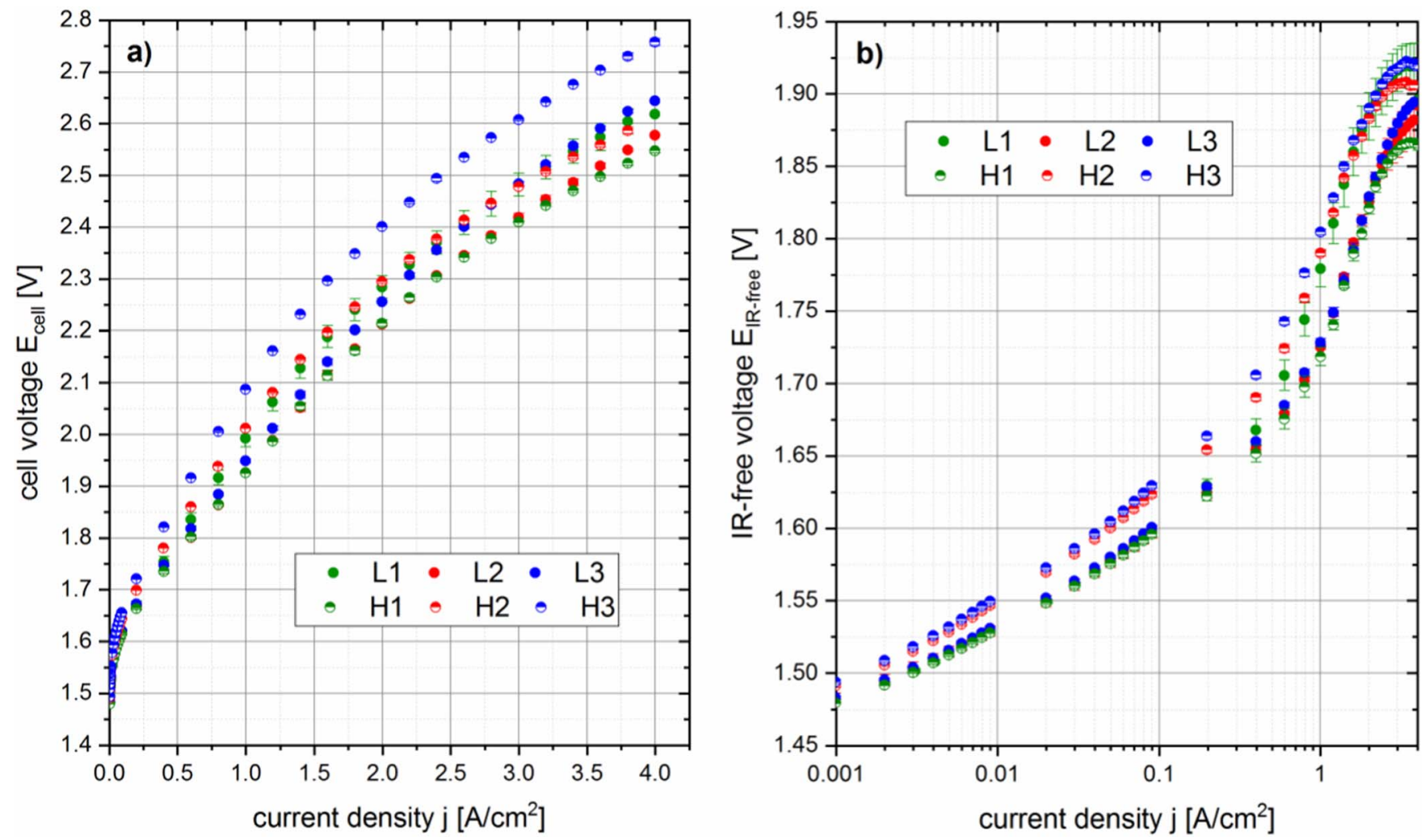

Figure 2. a) Polarization curves for cells with PTL materials $\mathrm{L} 1$ to $\mathrm{H} 3$, at $50^{\circ} \mathrm{C}$ and 10 bar balanced gas pressure; b) iR-free voltages for cells indicated.

In the first section the general performance is compared and the ohmic overpotential is analyzed. The second section provides insight into the influence of PTL morphology and topology on the kinetic and mass transport overpotentials and a new concept of a normalized PEWE mass transport resistance is introduced. The last section discusses the impact of PTL structures on cell thermal management. Effective thermal conductivity factors of PTLs are determined based on electrochemical data and compared to computed results of Part I. ${ }^{19}$

General cell performance.-The performance of PEWE cells with the 6 different Ti-fiber based PTLs, characterized at $50^{\circ} \mathrm{C}$ and 10 bar balanced pressure, is shown in Figure 2a). Error bars represent cell

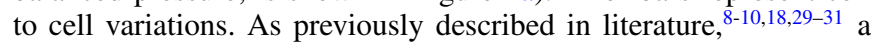
distinct influence of the PTL structure on cell performance is observed. Performance can be categorized into three groups. Group 1 (H3 and H2) features the highest cell voltages. Both samples have the highest porosity and largest solid feature size. Group 2 (L1 and L3) show an intermediate performance with overpotentials about of $100 \mathrm{mV}$ lower than for group 1. The best performing group 3 (L2 and H1) shows up to $200 \mathrm{mV}$ lower overpotentials.

IR-free cell and i/E polarization curves are given in Figure $2 b$ ). Focusing on the kinetic domain between 0.001 and $0.1 \mathrm{~A} / \mathrm{cm}^{2}$, group 1 shows the highest overpotentials, the difference increases to $50 \mathrm{mV}$ between 0.1 and $4 \mathrm{~A} / \mathrm{cm}^{2}$ in comparison to groups 2 and 3, which feature below $0.4 \mathrm{~A} / \mathrm{cm}^{2}$ almost identical voltage profiles in the iRfree representation.

Material L1, having the finest structure, shows a hybrid like behavior. It has the same kinetic behavior as group 3 and after a transition regime to a current density of $1.6 \mathrm{~A} / \mathrm{cm}^{2}$ the IR-free voltage reaches the voltage level of group 1 . These observations show that the different structures of the PTLs have a distinct impact on cell performance.

The influence on the kinetic and ohmic overpotentials is analyzed in the upcoming sections. The bending of the polarization curves at high current densities is associated to temperature increase, which is also discussed in the next section.
Ohmic overpotential. - The missing quantification of PTL surface and PTL/CL interface properties resulted in a lack of validation and correlation in literature. ${ }^{8,10,14,18,29}$ Here the interfacial contact areas, determined in Part $\mathrm{I},{ }^{19}$ are used to relate the PTL surface properties to HFR differences.

The HFR as function of current density is plotted in Figure 3a) for all six materials, with the powder sintered PTL T10 included for comparison. For T10 data by Suermann et al. ${ }^{8}$ at identical operation conditions and measured in the same cell and testbench is shown. The evolution of the HFR as function of increasing current density shows an uniform trend. The decrease at current densities above $1 \mathrm{~A} / \mathrm{cm}^{2}$ indicates a temperature effect with decreasing membrane resistance. Above about $2 \mathrm{~A} / \mathrm{cm}^{2}$ a linear decrease is observed. The difference in slope reflects the difference in thermal conductivity of the PTLs.

The quasi-isothermal plateau in the kinetic regime at current densities $<1 \mathrm{~A} / \mathrm{cm}^{2}$ enables a reliable comparison between the PTL materials. The cell with $\mathrm{H} 3$ shows the highest ohmic resistances of $\sim 315 \mathrm{~m} \Omega \mathrm{cm}^{2}$. Cells with $\mathrm{H} 2$ and L3 have HFRs $\sim 60$ and $70 \mathrm{~m} \Omega \mathrm{cm}^{2}$ lower and cells with L1, L2, H1 and T10 having resistances in the range of $220-230 \mathrm{~m} \Omega \mathrm{cm}^{2}$.

From these plateau HFR values the individual sub-resistances associated with the setup, the membrane and the so-called CL/PTL interfacial resistance can be determined according to Eq. 4. For the membrane N117 with a nominal dry thickness of $175 \mu \mathrm{m}$, an operando membrane thickness $t_{\text {mem }}$ of $\sim 210 \mu \mathrm{m}$ was chosen for calculation. This is based on a liquid water uptake of $21-23 \mathrm{~mol} / \mathrm{mol}^{22,27,32}$ resulting in through-plane swelling of 203 to $220 \mu \mathrm{m} .{ }^{33-35}$ With a specific membrane conductivity at $50^{\circ} \mathrm{C}$ of $0.1 \mathrm{~S} / \mathrm{cm},{ }^{32}$ and the experimentally determined ohmic set-up resistance of $\sim 15 \mathrm{~m} \Omega \mathrm{cm}^{2}$, the remaining variable resistance is assigned to the interfacial resistance, which is a function of the PTL interface structure.

These sub-resistances are given for a low current density $\left(0.03 \mathrm{~A} / \mathrm{cm}^{2}\right)$ in the quasi-isothermal regime and at high current density of $\left(3 \mathrm{~A} / \mathrm{cm}^{2}\right)$ in Figure $\left.3 \mathrm{~b}\right)$. At the high current density the membrane resistances are lower and differ between PTLs due to differences of membrane temperature caused by differences in thermal 

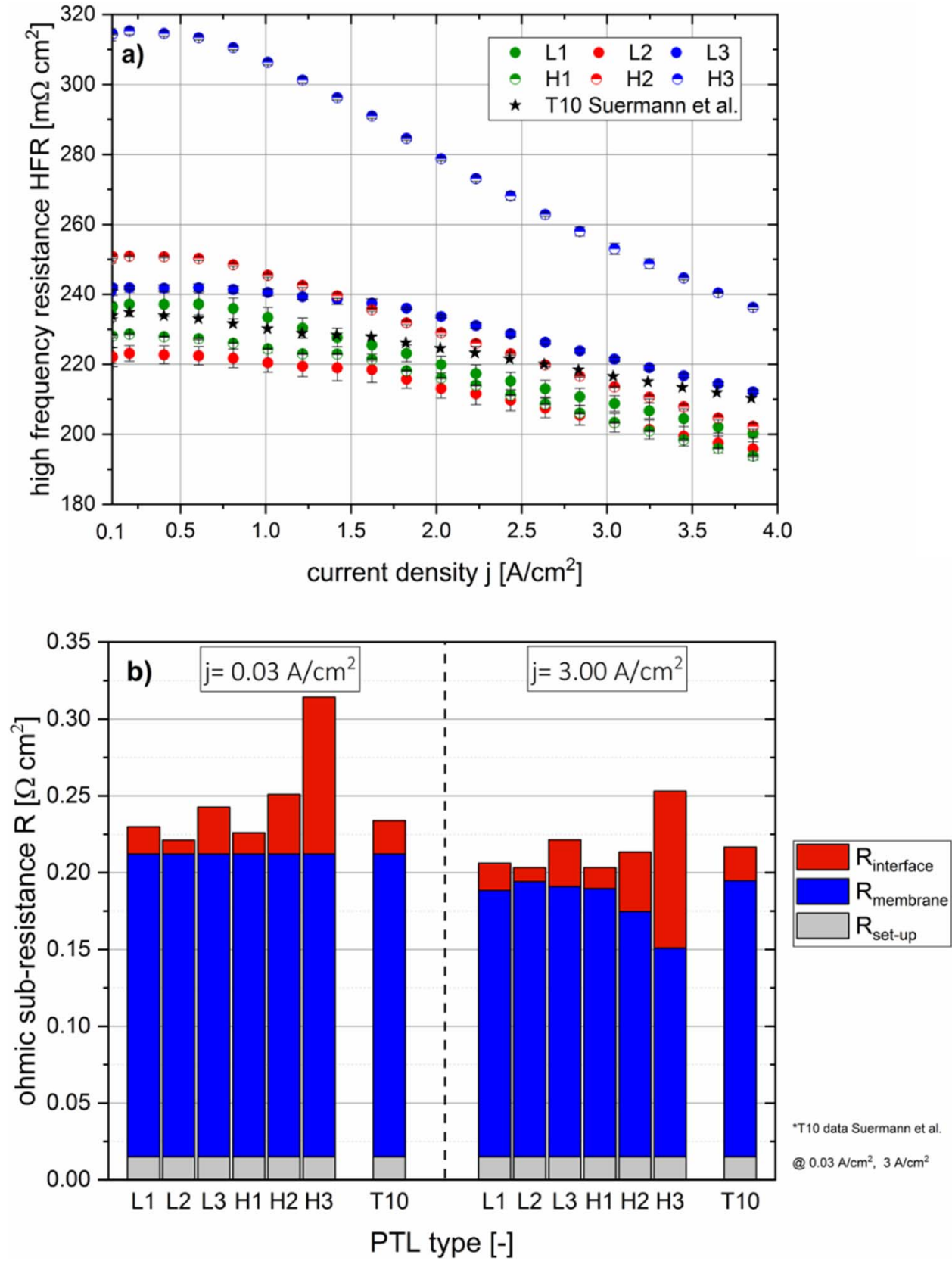

Figure 3. a) High frequency resistance as function of current density at $50^{\circ} \mathrm{C}$ and 10 bar balanced gas pressure; membrane used is Nafion $\mathrm{N} 117$; data for T10 included from Suermann et al. $;^{8}$ b) sub-resistances associated to membrane, set up and interface in the kinetic regime at $0.03 \mathrm{~A} / \mathrm{cm}^{2}$ and in the mass transport regime at $3 \mathrm{~A} / \mathrm{cm}^{2}$.

conductivities of the PTLs. Results for low $j$ are also summarized in Table I.

When comparing the trend of the interfacial resistances to the PTL surface properties, it is observed that the trend of resistances is opposite to the trend of the specific interfacial contact area $R_{I C A}$ reported in Part I. ${ }^{19}$ Materials L1, L2, H1 and T10 feature an $R_{I C A}$ in the range of $1.6-1.8 \mathrm{~m}^{2} / \mathrm{m}^{2}$ corresponding to interfacial resistances of 9-22 $\mathrm{m} \Omega \mathrm{cm}^{2}$. For L3 and $\mathrm{H} 2$ with a significantly lower $R_{I C A}$ of 1.0 and $1.1 \mathrm{~m}^{2} / \mathrm{m}^{2}$ the interfacial resistance increases to 30 to $39 \mathrm{~m} \Omega \mathrm{cm}^{2}$, while $\mathrm{H} 3$, with the lowest contact area of $0.76 \mathrm{~m}^{2} / \mathrm{m}^{2}$ has an interfacial resistance of $102 \mathrm{~m} \Omega \mathrm{cm}^{2}$. This opposite trend between interfacial area and interfacial resistance can be understood when the resistance is correlated to the actual microscopic, interfacial area between PTL and CL. For all PTLs, except H3, where the extreme membrane deformation seems to cause additional effects, this microscopic contact resistance of one PTL has a constant value of $15 \pm 4.5 \mathrm{~m} \Omega \mathrm{cm}^{2}$ normalized to interfacial contact area of the PTLs.

This analysis highlights the influence of the surface structure on HFR and shows the importance of the thermal conductivity of the PTL when interpreting HFR data.

Kinetic overpotential. - The IR-free voltages of cells with the different PTLs are given in Figure 4. The Tafel slopes are determined in the current density window of 5 to $80 \mathrm{~mA} / \mathrm{cm}^{2}$ and feature similar values between 64 and $70 \mathrm{mV} / \mathrm{dec}$, but at different absolute overvoltages.

The different apparent exchange current densities indicate an influence of the PTL interface structure on the utilization of the catalyst layer. Cells with $\mathrm{H} 3$ and $\mathrm{H} 2$ show the highest voltages, i.e. lowest exchange current density. The activation losses with L-type PTLs and $\mathrm{H} 1$ are comparable and in average $20 \mathrm{mV}$ lower than for $\mathrm{H} 2$ and $\mathrm{H} 3$. 


\begin{tabular}{|c|c|c|c|}
\hline $\begin{array}{c}\text { PTL type } \\
-\end{array}$ & $\begin{array}{c}\mathrm{R}_{\mathrm{mem}} @ 30 \mathrm{~mA} / \mathrm{cm}^{2} \\
\Omega \mathrm{cm}^{2}\end{array}$ & $\begin{array}{l}R_{\text {inter }} \\
\Omega \mathrm{cm}^{2}\end{array}$ & $\begin{array}{l}R_{\text {set-up }} \\
\Omega \mathrm{cm}^{2}\end{array}$ \\
\hline$L 1$ & \multirow{7}{*}{0.197} & 0.020 & \multirow{7}{*}{0.015} \\
\hline$L 2$ & & 0.009 & \\
\hline$L 3$ & & 0.030 & \\
\hline$H 1$ & & 0.014 & \\
\hline$H 2$ & & 0.039 & \\
\hline H3 & & 0.102 & \\
\hline$T 10$ & & 0.022 & \\
\hline
\end{tabular}

As can be seen from the inset in Figure 4, while the differences within the groups are within the experimental standard deviations of cell to cell measurements, they still appear to follow the general trend along with the ICA trend reported in Part I, ${ }^{19}$ i.e. $\eta_{k i n} \mathrm{~L} 3>\mathrm{L} 1, \mathrm{~L} 2, \mathrm{H} 1$ corresponds to ICA L3 $<\mathrm{L} 1, \mathrm{~L} 2, \mathrm{H} 1$.

According to Eq. 8, the ratios of current densities at constant kinetic overpotential, i.e. constant IR-free cell voltage in the kinetic regime, directly reflect the ratios of utilization factors. The ratios are determined at $1.55 \mathrm{~V}$, which avoids influence by mass transport (starting to appear at current densities $\left.>0.1 \mathrm{~A} / \mathrm{cm}^{2}\right)^{6,8,36}$ and the relative utilization factors $X$ are calculated according to Eq. 8 relative to L1, the material having the finest surface structure. The results are given in Table II.

The overall trend of $\mathrm{X}$ is in accordance with the specific interfacial contact area $\mathrm{R}_{\mathrm{ICA}}$ determined in Part $\mathrm{I},{ }^{19}$ for clarity also reported in Table II here. PTLs with high interfacial contact areas also have high catalytically active surface areas. For L1, L2, H1, featuring a similar $\mathrm{R}_{\mathrm{ICA}}$ in the range of 1.6 to $1.8 \mathrm{~m}^{2} / \mathrm{m}^{2}$, relative catalyst utilizations $\mathrm{X}$ of 0.96 to 1.02 are determined. PTLs having lower interfacial contact areas also show lower utilization factors. Utilization decreases to 0.52 and 0.47 at $\mathrm{R}_{\mathrm{ICA}}$ values of $0.55 \mathrm{~m}^{2} / \mathrm{m}^{2}$ and $0.42 \mathrm{~m}^{2} / \mathrm{m}^{2}$ for $\mathrm{H} 2$ and $\mathrm{H} 3$, respectively.

The differences in catalyst layer utilization imply that the use of geometrically normalized mass transport overpotentials may not be the most adequate way for correlating PTL bulk properties to mass

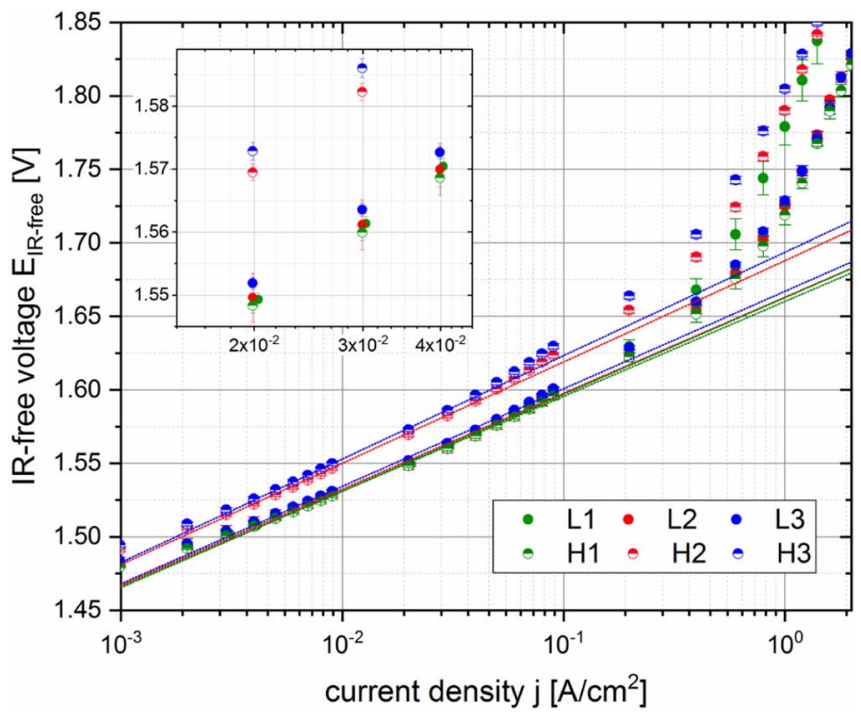

Figure 4. iR-free cell voltages as function of current densities at $50^{\circ} \mathrm{C}$ and 10 bar balanced gas pressure; Tafel slopes determined by linear regressions between 5 and $80 \mathrm{~mA} / \mathrm{cm}^{2}$; inset shows magnification of low current density region.

\section{Table II. Tafel slope $b$ and current density $j$ at $1.55 \mathrm{~V}$ are given for all PTL types. Catalyst layer utilization factors $X$ are normalized to $L 1$. Specific interfacial contact areas $R_{I C A}$, characterized in Part $I^{19}$ of this study, is reported to show correlation.}

\begin{tabular}{cccccccl} 
PTL type & unit & L1 & L2 & L3 & H1 & H2 & H3 \\
\hline$b$ & $\mathrm{mV} / \mathrm{dec}$ & $66 \pm 1$ & $64 \pm 1$ & $65 \pm 1$ & $64 \pm 1$ & $69 \pm 2$ & $70 \pm 4$ \\
$j @ 1.55 \mathrm{~V}$ & $\mathrm{~mA} / \mathrm{cm}^{2}$ & 19.3 & 18.6 & 17.2 & 19.7 & 10.0 & 9.1 \\
$X$ & - & 1.00 & 0.96 & 0.89 & 1.02 & 0.52 & 0.47 \\
$R_{I C A}$ & $\mathrm{~m}^{2} / \mathrm{m}^{2}$ & 1.81 & & 1.11 & 1.57 & & 0.76
\end{tabular}

transport losses. A correction of $\eta_{m t x}$ with the relative utilization factor leads to the underlying relation, as discussed in the next section.

Mass transport overpotential.-The mass transport overpotentials are obtained by correcting cell voltages reported in Figure 2 with reversible cell voltage, and ohmic and kinetic overpotentials, according to Eq. 1 and are given in Figure 5a). Here, the materials can be
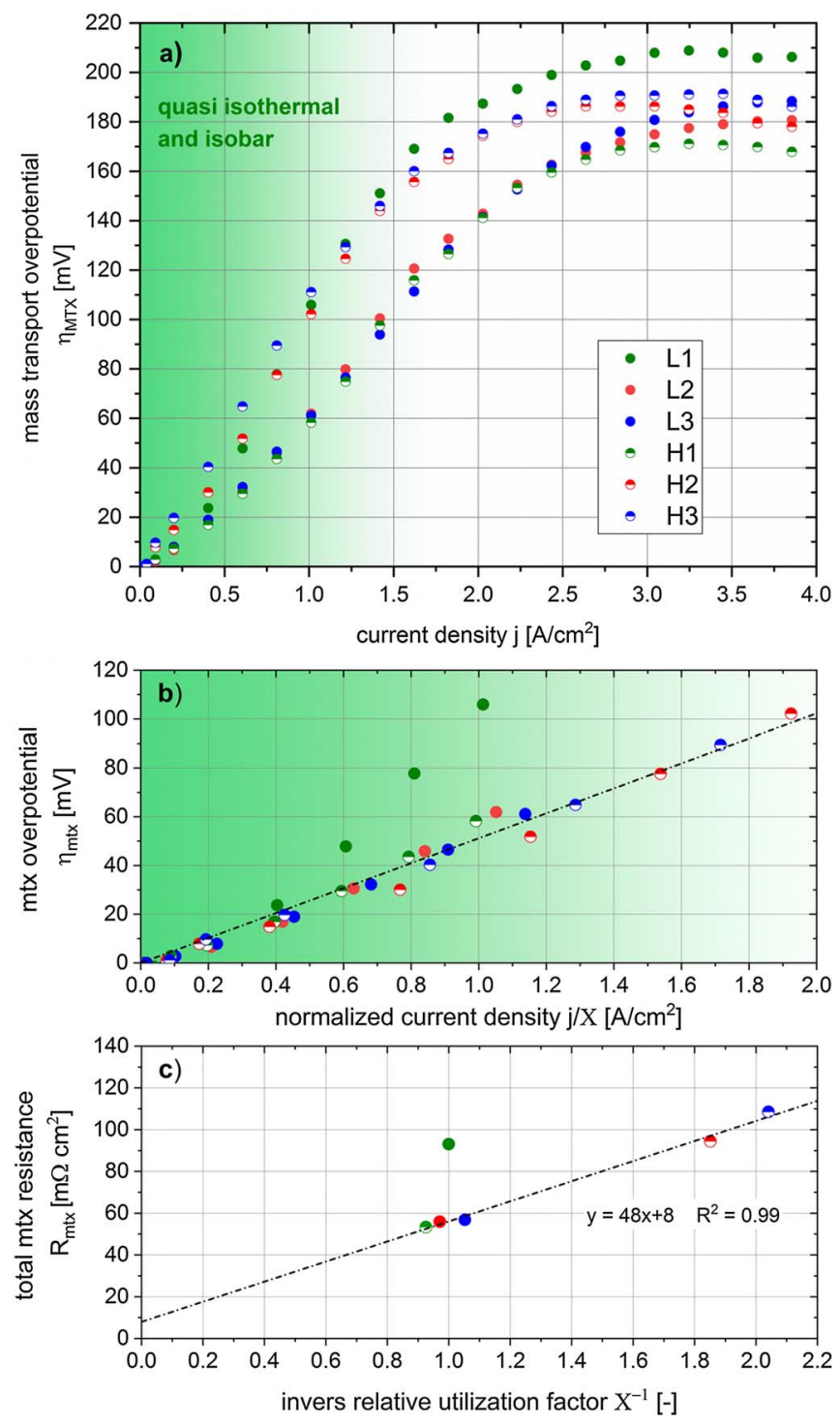

Figure 5. a) Mass transport overpotential as function of current densities at $50^{\circ} \mathrm{C}$ and 10 bar balanced gas pressure; b) mass transport overpotential as function of utilization factor $X$ normalized current density; c) total mass transport resistance plotted versus inverse utilization factor $X^{-1}$, green shaded area represents the quasi-isothermal domain. 
categorized into two groups. The first group comprises L2, L3 as well as $\mathrm{H} 1$ and shows similar overpotentials up to $2.5 \mathrm{~A} / \mathrm{cm}^{2}$, about $40 \mathrm{mV}$ lower at $1 \mathrm{~A} / \mathrm{cm}^{2}$ than for the second group comprising $\mathrm{H} 2$ and $\mathrm{H} 3$. Careful analysis shows that L1 has a special, hybrid-like behavior. Despite same behavior as L2, L3 and H1 in the kinetic regime, overpotential of L1 starts to deviate significantly at higher current densities $\left(>0.5 \mathrm{~A} / \mathrm{cm}^{2}\right)$ and approaches/exceeds overpotentials of $\mathrm{H} 2$ and $\mathrm{H} 3$ at high current densities.

In analogy to the HFR analysis, a temperature effect is observed for all PTL types. At current densities above $2 \mathrm{~A} / \mathrm{cm}^{2}$, mass transport overpotentials show a distinct flattening deviation from the linear behavior. In Figure 5a) quasi-isothermal conditions (as indicated by HFR in Figure 3) are obtained only in the green shaded domain up to about $1 \mathrm{~A} / \mathrm{cm}^{2}$.

The direct correlation of the PTL bulk properties to mass transport overpotentials as function of geometrically normalized parameters such as current density may lead to a misinterpretation of governing resistances. The analysis of the kinetic overvoltage showed that the PTL surface structure has a direct influence on the catalyst layer utilization with i.e. $\mathrm{H} 2$ and $\mathrm{H} 3$ having about a $50 \%$ lower utilization. As a consequence, it is proposed to relate the mass transport resistance to the fraction of active catalyst layer only. The catalyst layer resistance is considered as a local resistance scaling with active catalytic surface given as the utilization factor $X$ according to Eq. 10 . Therefore, the mass transport overpotential is related to a normalized current density based on the catalyst layer utilization (see Table I) and is plotted in Figure 5b) for the quasi isothermal regime. It increases linearly with normalized current density for all materials, except for L1, which shows a stronger increase.

What makes L1 different? Cells assembled with L1 show same kinetic activity as for PTL materials L2, L3 and H1 but L1 features the lowest average pore and throat sizes. The bottlenecks, the small connections between pores, quantified by virtual mercury intrusion porosimetry pore size distribution (MIP-PSD) in Part $\mathrm{I}^{19}$ of this study, appear to be a sensitive parameter for fluid transport. The pore size at $50 \%$ cumulative pore volume of MIP-PSD $d_{M I P, 50}$ is considered as relevant parameter for bottleneck size. L1, features a $d_{M I P, 50}$ size of $14 \mu \mathrm{m}$, smaller than all other materials. The cells with L1 show mass transport overpotentials up to $50 \mathrm{mV}$ higher than the ones with L2 which has second smallest $d_{M I P, 50}$ of $17 \mu \mathrm{m}$ (see Figure 5a).

This result indicates that the bottle-neck size may have a critical threshold for liquid/gas transport in the PTL bulk. When $d_{M I P, 50}=$ $14 \mathrm{um}$ is considered as relevant for bottleneck sizes for fiber based PTL materials, then this value is close to the value of $10-13 \mu \mathrm{m}$ which was stated in literature as lower critical pores size for PTL for PEWE operation. ${ }^{18,37}$ The characteristically narrow pore size distribution of the fiber materials might have an additional impact on the fluid transport. In contrast to sinter materials featuring wide pore size distributions, ${ }^{8}$ for the fiber materials there is a lower statistical probability for neighboring big pores facilitating fluid transport. A detailed analysis of bulk structure and throat size distribution rather than determination of mean pore sizes will be key to comprehensive understanding of this phenomenon, as today the underlying governing processes are not known. The water transport in the PTL bulk could be hindered by local narrow bottlenecks in the pore matrix and thus a local under-supply of water in the catalyst layer may occur at increasing current densities. More studies have to be conducted to understand the phenomena. Time resolved 3D operando imaging of the PTL bulk two-phase behavior could provide explanations.

The similar increase of mass transport overpotential with normalized current density for L2 to $\mathrm{H} 3$ in Figure 5b) implies a governing mass transport resistance which is not affected by the PTL bulk properties for pore sizes above the threshold value discussed above. It appears that the resistance is rather associated to a local mass transport in the catalyst layer than to the fluid transport in the PTL bulk. When the total mass transport resistance $R_{m t x}$, determined by linear regressions in the quasi isothermal regime up to $2 \mathrm{~A} / \mathrm{cm}^{2}$ in Figure $5 \mathrm{a}$ ), is plotted versus the inverse utilization factor $X^{-1}$, a linear dependence is observed for all materials L2 to $\mathrm{H} 3$ in Figure $5 \mathrm{c}$ ). The intercept represents, according to Eq. 11, the mass transport resistance in the PTL bulk,
Table III. Through plane thermal conductivities $\sigma_{\text {thermal }}$ (from Part $I^{19}$ of this study) and values for $\sigma_{\text {eff }}$ obtained from electrochemical measurements.

\begin{tabular}{cccccccc} 
Fiber type & unit & L1 & L2 & L3 & H1 & H2 & H3 \\
\hline$\sigma_{\text {thermal }}{ }^{19}$ & $\mathrm{~W} /(\mathrm{mK})$ & 5.9 & 5.8 & 4.5 & 2.1 & 2.4 & 1.7 \\
$\sigma_{\text {eff }}$ & $\mathrm{W} /(\mathrm{mK})$ & 5.5 & 6.3 & 5.3 & 3.6 & 3.0 & 1.6
\end{tabular}

having only minor contribution of $\sim 10 \%$ to the total mass transport resistance. Therefore the processes in the catalyst layer appear to dominate mass overpotentials for the material matrix investigated in this study.

The phenomena of a microscopically governing local resistances in the catalyst layer ${ }^{23,38-42}$ is in line with recent findings for polymer electrolyte fuel cells by Schuler, Chowdhury et al. ${ }^{24}$ showing that the local catalyst layer resistance is governed by species transport through the ionomer and its interface.

Heat management.-Efficient heat management in the cell represents a main engineering challenge to overcome. ${ }^{43-46}$ In particular the thermal conductivity of the PTLs $\sigma_{\text {therm }}$ features a critical parameter. The investigated materials show conductivity differences over an order of magnitude from 1 to $10 \mathrm{~W} /(\mathrm{mK}),{ }^{8,12}$ see Part I. ${ }^{19}$ In all PTLs the heat conductivity of the solid titanium matrix is considerably higher than that of the gas/water filled pores, which have at least a two orders of magnitude lower thermal conductivity. Therefore the thermal properties of the solid skeleton govern the heat management. Here a simple methodology is shown, that can be used for extracting the effective thermal conductivity $\sigma_{e f f}$ of PTLs from electrochemical data.

The average temperature increase of the membrane is determined from the membrane conductivity, as given in Eq. 4, and the temperature dependent ionic conductivity correlation in Eq. 12. The interfacial and set up resistances reported in Table I are used for calculation. Data for T10, measured at identical operation and set up conditions by Suermann et al., ${ }^{8}$ is included as reference.

The temperature at the catalyst layer/membrane is a result of the heat produced based on the different overpotentials and the heat conduction in the PTL. Therefore the differences in thermal conductivity directly influence the temperature profiles across the membrane/CL/PTL sandwich. At low overpotentials and heat production rates (generally at $<1 \mathrm{~A} / \mathrm{cm}^{2}$ ) only small temperature gradients are observed. At the standard current density of $2 \mathrm{~A} / \mathrm{cm}^{2}$, L type PTLs, as well as $\mathrm{H} 1$ and $\mathrm{T} 10$ feature almost identical temperature increases of $\sim 5 \mathrm{~K}$ while increases of $13 \mathrm{~K}$ and $22 \mathrm{~K}$ for $\mathrm{H} 2$ and $\mathrm{H} 3$ respectively, are observed, showing that low thermal conductivities have a significant impact on the heat management.

From the HFR data and correlated temperature increase, the effective thermal conductivity $\sigma_{e f f}$ of the PTLs can be determined. The product of heat flux and total PTL thickness $\dot{q}^{*}$ has a linear relation to the temperature difference $\Delta \overline{\mathrm{T}}_{\text {mem }}$, as shown in Figure 6 . The effective thermal conductivity $\sigma_{\text {eff }}$ of the PTL type is then given by the slope of this linear relation according to Eq. 13.

L1 to L3 show similar heat conductivities in the range of 5.3 to $6.3 \mathrm{~W} /(\mathrm{mK})$. The materials with higher porosities have lower thermal conductivities, with $\mathrm{H} 1$ having $3.6 \mathrm{~W} /(\mathrm{mK})$, while for $\mathrm{H} 2$ and $\mathrm{H} 3$ it drops to 3.0 and $1.6 \mathrm{~W} /(\mathrm{mK})$, respectively. These electrochemically determined effective thermal conductivities are in good accordance with the conductivities computed ex situ based on the XTM structures, see Table III. The comparison of both methods reveals that throughplane conductivity dominates heat transport in a PTL. This validation shows that the electrochemical method is a useful tool for thermal PTL characterization.

\section{Discussion}

Which PTL surface parameter is governing catalyst layer utilization?-The influence of the PTL surface properties on kinetic, electric and mass transport overpotential implies that the catalyst layer 

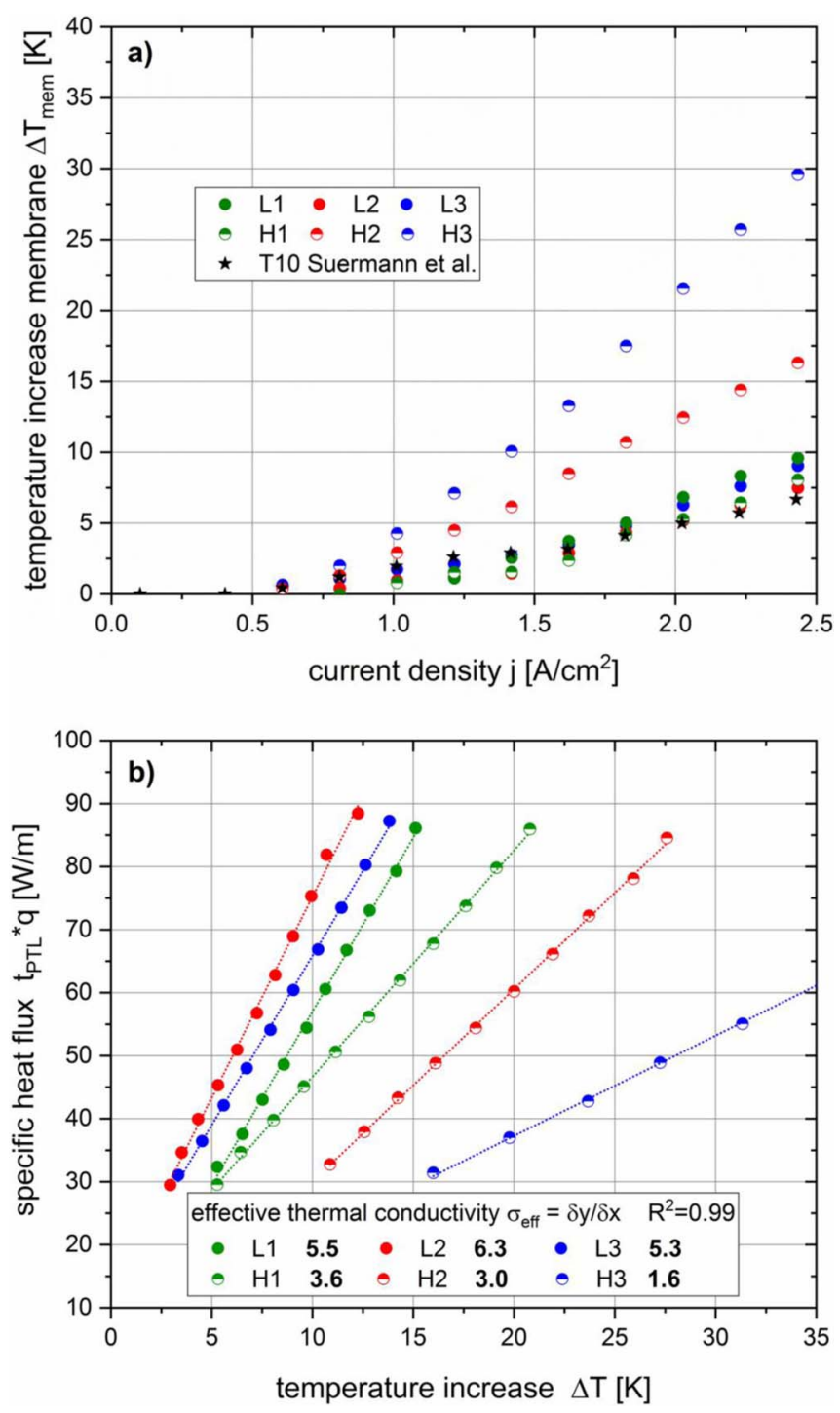

Figure 6. a) HFR as function of current density at $50^{\circ} \mathrm{C}$ and 10 bar balanced gas pressure; data for T10 from Suermann et al. ${ }^{8}$ b) shows the specific heat flux as function of temperature increase of the membrane. The slope of the linear regression equates the effective thermal conductivity of the PTL, which is given in the caption and Table III.

is only partially utilized. The question arises, which of the structural properties of PTL/CL interface is the governing parameter? In the section Kinetic overpotentials we have seen that the utilization (qualitatively) correlates with the interfacial contact area $R_{I C A}$. At the interfacial contact area, the electric charge and heat is supplied/removed the easiest (red lines in inset Figure 7). According to results obtained from optical imaging of operando cells,${ }^{15}$ gas evolution i.e. catalytic activity was predominantly observed at the "triple phase" lines where all three phases of water/catalyst layer/PTL share contact. Here we define these lines as interfacial contact lines $R_{I C L}$, denoted as blue dots in the 2D-representation in the inset in Figure 7. Finally it cannot be excluded that the interfacial area facing the water, governs catalyst utilization as here the supply with water is the easiest. This area is denoted "interfacial non-contact areas" $R_{I N C A}$ and shown in green lines. Figure 7 shows the surface parameters $R_{I C A}, R_{I C L}$ and $R_{I N C A}$ normalized to material with the largest value as function of the utilization factor $X$ which is normalized to $\mathrm{H} 1$.

$R_{I N C A}$, the catalyst layer area facing the water, shows no correlation with the catalyst utilization, so it is obviously not the governing parameter for the catalyst utilization. $R_{I C L}$, the triple phase line fea-

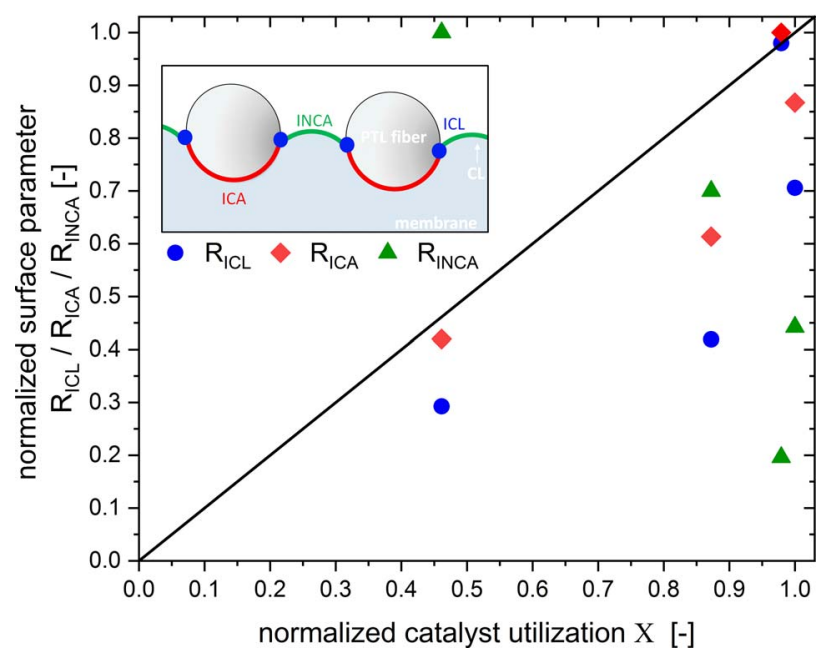

Figure 7. Normalized PTL surface parameters $R_{I C A}$ (interfacial contact area), $R_{I N C A}$ (interfacial non contacted area) and $R_{I C L}$ (interfacial contact line, i.e. triple phase line) plotted as function of normalized catalyst layer utilization. Normalization is based on the maximum value of the respective parameter.

tures the correct trend, but shows a lower correlation than $R_{I C A}$, the contact area. $R_{I C A}$ shows the best fit and is therefore expected to be the dominant governing parameter for catalyst utilization. However, still the governing regime could be a combination of the contacted areas and the triple phase lines. From the present analysis, it is not clear how complete catalyst layers are utilized under the solid particles nor if surrounding areas next to the triple phase lines have also electrochemical activity.

Which is the governing process, limiting catalyst layer utilization?-The question, which is the underlying resistance causing the phenomena limiting catalyst layer utilization is still not understood. Three processes have the potential to cause the dominant resistance: fluid, electric and ionic transport. A schematic of an anodic PEWE half cell and close-up of the PTL/CL interface exemplifies the three processes in Figure 8.

Process 1: Fluid transport, occurring between the pore space in the PTL and the secondary pore space in the catalyst, is shown in red in Figure 8. Water is permeating from the PTL bulk pore space and has to propagate in in-plane direction in the catalyst layer to reach domains beneath the PTL contacted areas. The above analysis gives no indications that this transport would be limiting. This is due to either a low tortuosity in the catalyst pore space and/or the high molar concentration of liquid water.

Process 2: Ionic transport, highlighted in blue, in the catalyst layer occurs perpendicular towards the membrane and is thus the same for the different domains $\left(R_{I C A}, R_{I C L}\right.$ and $\left.R_{I N C A}\right)$. The through-plane transport length (catalyst layer thickness) is up to 10 times less than the in-plane distance (associated to the pore radius, i.e. distance between fibers) in the range of $30 \mu \mathrm{m}$ to $50 \mu \mathrm{m}$. It is known that confinement effects for ionomer thin films leads to reduced ionic conductivity up to an order in magnitude ${ }^{32,47,48}$ compared to membrane bulk. Assuming a conductivity of 0.1 and $0.01 \mathrm{~S} / \mathrm{cm}$, a catalyst layer thickness $t_{c l}$ of $10 \mu \mathrm{m}$, a wet ionomer volume content of $25 \%$ vol,tot (ionomer content $11.6 \mathrm{wt} \%)^{36}$ and tortuosity of 2 , the ionic resistance is determined to be $10^{-2}$ to $10^{-1} \Omega \mathrm{cm}^{2}$. This relatively low resistance does not imply to cause the observed catalyst layer utilization phenomena.

Process 3: Electric transport in the catalyst layer occurs predominately in through-plane direction under the PTL fibers and in in-plane direction for the electrically non-contacted catalyst layer in PTL pores due to comparably large distances between fibers in contact with the CL. 


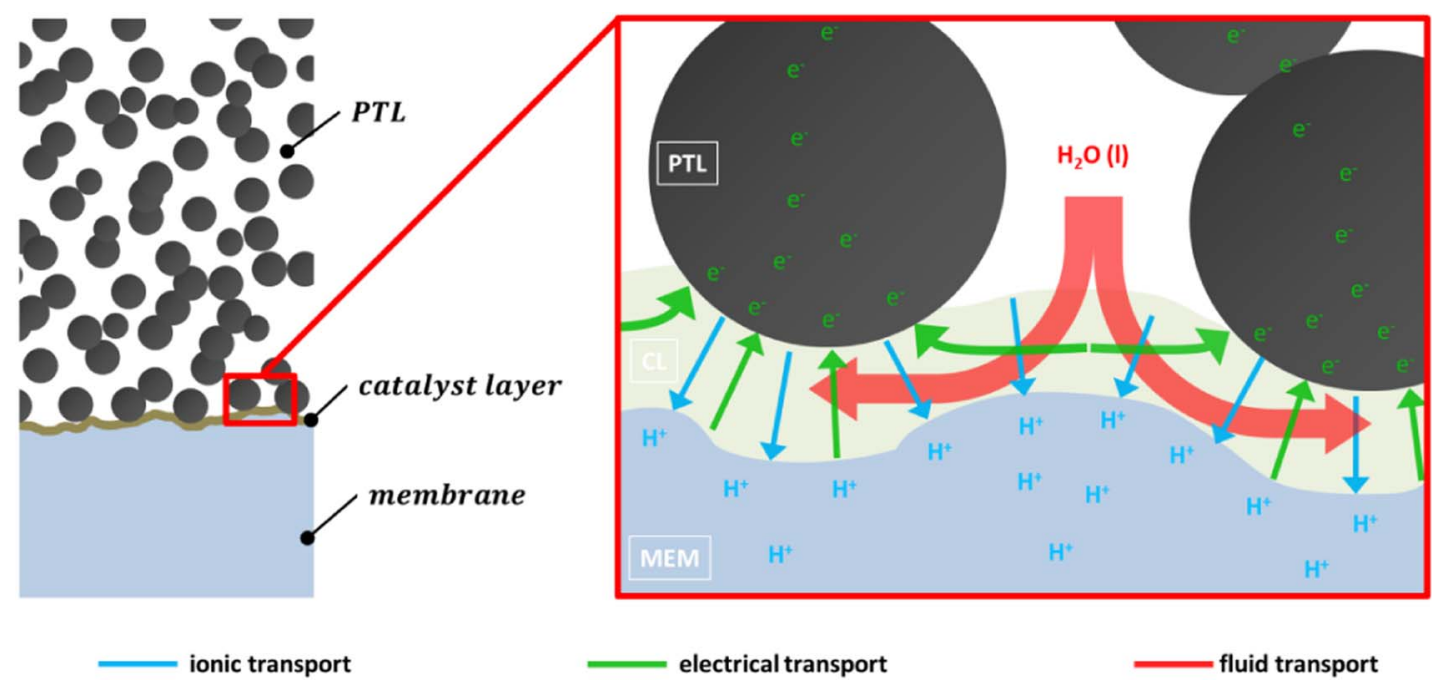

Figure 8. Schematic of anodic half-cell cross-section of PTL, catalyst layer and membrane; zoom of the interface of PTL and catalyst layer; the transport of ions is shown in blue, of electrons in green and of water in red.

Mechanically induced stress and strain by PTL contact points results in morphological changes in the catalyst layer. Distortion of the electric percolating network by micro crack formation may then to have an impact on in-plane conductivity. Post operando SEM images of anodic catalyst layer surfaces, shown in Figures 9a) and 9b) reveal such micro crack formation parallel to the PTL fiber imprints due to massive catalyst layer and membrane deformation, highlighted in red.
Furthermore fractures caused by catalyst layer and membrane tension in PTL pores can be observed, colored in yellow.

Figure 9c) exemplifies the impact of mechanical catalyst layer deformation by mechanical interference with PTL fibers. Micro cracks in bent CL regions highlighted in red, green and yellow are formed. In particular, yellow and red cracks interfere with the required electric in-plane conductivity causing higher in-plane resistances, while
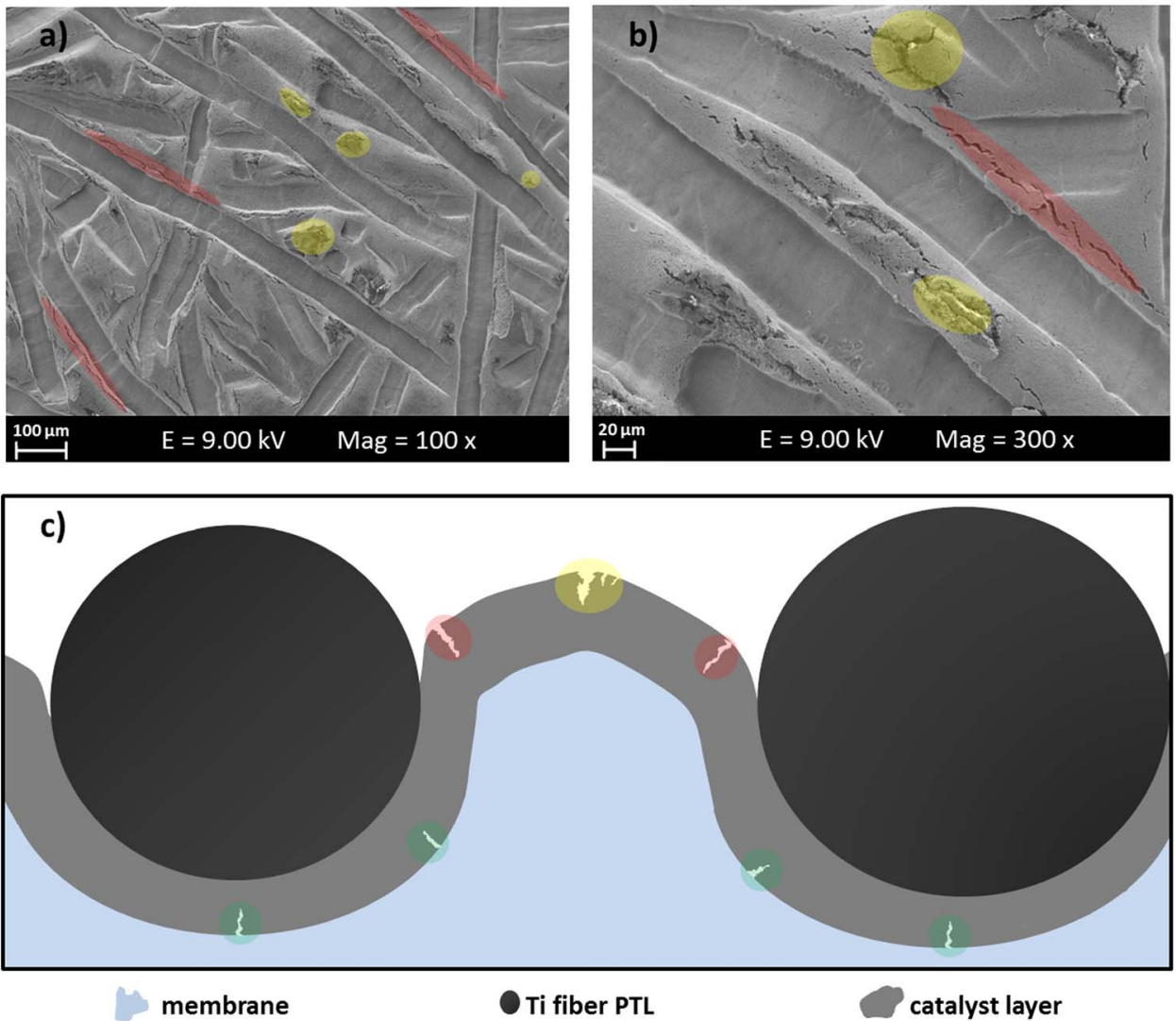

Figure 9. a) and b) post operando SEM images of anode catalyst layer surfaces with magnifications indicated, tension induced micro-cracks colored in red and compression fractures in yellow; c) cartoon of cross-section indicating crack classes. 
green cracks below the fibers are unimportant, as here also the electric transport occurs in through-plane direction.

The phenomena of catalyst layer conductivity dependence on water activity is well known in the field of $\mathrm{PEMFC}^{45}$ and associated to the effect of ionomer swelling. ${ }^{49,50}$ A disruption of the electric conduction due to missing catalyst layer compression in the relatively large PTL pores of the $R_{I N C A}$ region can be another factor leading to high electric in-plane resistances and non-utilization of the catalyst in the $R_{I N C A}$ areas.

The above reasoning is indications, but not proof that the electric resistance is the origin of the reduced CL utilization. Anodic water consumption and electro osmotic drag effect may limit ionomer conductivity in the catalyst layer. But this would rather be in the thickness direction and not correlate with interfacial contact areas. Furthermore the access of water/removal of gas seems not to be limiting, this supports the hypothesis that the active domains in the catalyst layer must be located at least in the vicinity of the triple phase lines.

\section{Conclusions}

A systematic matrix of six Ti-fiber PTL materials with different of bulk and surface properties was characterized in PEWE cells for cell performance. The results contribute to the understanding of the correlation of PTL bulk and surface properties on overpotentials in PEWE operation. Performance in polarization curves was analyzed for the three main overpotentials and was correlated to the structural properties. As a consequence, design guidelines can be deduced for better performing PTLs.

Main findings are that for the investigated set of Ti-fiber materials, the surface property of the PTL is the dominant parameter influencing the performance and not the bulk transport, except for heat conductivity. It is found that the interfacial contact area between PTL and catalyst layer governs contact resistance and is the major player, for limitation of catalyst utilization. Utilization is reduced due to high electric resistance in the part of the catalyst layer, not being in direct contact with the fibers, which is lacking compression force and develops cracks. Results also show that transport in the catalyst layer rather than PTL bulk dominates the mass transport overpotential based on the characteristics of a local resistance, as previously reported for polymer electrolyte fuel cells. ${ }^{23,24}$

These findings of correlation between structural properties and cell performance lead to the following design guidelines for PTL:

- interface of PTL and CL has an impact on all overpotentials - higher interfacial contact areas also result in lower ohmic overpotentials due to reduced ohmic contact resistances

- higher interfacial contact areas between PTL and CL result in lower kinetic overpotentials associated with higher utilization of the catalyst layer

$\circ$ mass transport overpotential scales inversely with catalyst layer utilization

$\circ$ the catalyst layer resistance dominating mass transport overpotential shows local resistance behavior ${ }^{23,24}$

- bulk morphology of PTLs is not dominating mass transport overpotential when throat sizes in the PTL exceed given values

$\circ$ results indicate that for this class of fiber based PTLs pore sizes smaller $d_{M I P, 50} \sim 14 \mu \mathrm{m}$ lead to an increased mass transport overpotential. If this is a general case for all types of PTL needs further investigation

$\circ$ the bulk transport parameters permeability and diffusivity did not show any correlation with performance. It is hypothesized that as long as both are above an (unknown) threshold, these are not limiting parameters for PTL materials

- thermal conductivity plays a crucial role for heat management, in particular when thick membranes, such as Nafion 117 are used

- PTL through-plane conductivity dominates

- lower porosity and finer solid PTL feature sizes lead to higher effective heat conductivity
- computed thermal conductivities based on XTM structures represent an accurate approximation of the effective thermal conductivities in operated cells

\section{Acknowledgments}

The authors would like to thank the Swiss Federal Office of Energy (SFOE, grant no SI/501331-01) for funding of the project in the framework of the Energy System Integration Platform at PSI. Jonathan Halter and Thomas Gloor are gratefully acknowledged for their scientific and technical support. We also thank Greenerity $\mathrm{GmbH}$ (Germany, Hanau-Wolfgang) for the permission for post operando SEM imaging of CCMs.

\section{ORCID}

Tobias Schuler (D) https://orcid.org/0000-0002-3954-2531

Thomas J. Schmidt (D) https://orcid.org/0000-0002-1636-367X

Felix N. Büchi (D) https://orcid.org/0000-0002-3541-4591

\section{References}

1. F. Mueller-Langer, E. Tzimas, M. Kaltschmitt, and S. Peteves, International Journal of Hydrogen Energy, 32, 3797 (2007).

2. M. Kopp, D. Coleman, C. Stiller, K. Scheffer, J. Aichinger, and B. Scheppat, International Journal of Hydrogen Energy.

3. S. A. Grigoriev, V. I. Porembsky, and V. N. Fateev, International Journal of Hydrogen Energy, 31, 171 (2006)

4. U. Babic, M. Suermann, F. N. Büchi, L. Gubler, and T. J. Schmidt, Journal of The Electrochemical Society, 164, F387 (2017).

5. A. Tremel, P. Wasserscheid, M. Baldauf, and T. Hammer, International Journal of Hydrogen Energy, 40, 11457 (2015).

6. M. Suermann, T. J. Schmidt, and F. N. Büchi, Ecs Transactions, 1141 (2015).

7. M. Suermann, T. J. Schmidt, and F. N. Büchi, Electrochim Acta, 211, 989 (2016).

8. M. Suermann, K. Takanohashi, A. Lamibrac, T. J. Schmidt, and F. N. Büchi, Journal of The Electrochemical Society, 164, F973 (2017).

9. P. Lettenmeier, S. Kolb, F. Burggraf, A. S. Gago, and K. A. Friedrich, J Power Sources, 311, 153 (2016)

10. H. Ito, T. Maeda, A. Nakano, A. Kato, and T. Yoshida, Electrochim Acta, 100, 242 (2013).

11. Z. Kang, J. Mo, G. Yang, S. Retterer, D. Cullen, T. Toops, J. Green Jr, M. Mench, and F.-Y. Zhang, Energy and environmental science, 10, 166 (2017).

12. L. Zielke, A. Fallisch, N. Paust, R. Zengerle, and S. Thiele, Rsc Adv, 4, 58888 (2014).

13. T. Bystron, M. Vesely, M. Paidar, G. Papakonstantinou, K. Sundmacher, B. Bensmann, R. Hanke-Rauschenbach, and K. Bouzek, Journal of Applied Electrochemistry, 48, 713 (2018).

14. P. Lettenmeier, S. Kolb, N. Sata, A. Fallisch, L. Zielke, S. Thiele, A. S. Gago, and K. A. Friedrich, Energy \& Environmental Science, 10, 2521 (2017).

15. J. Mo, Z. Kang, G. Yang, Y. Li, S. T. Retterer, D. A. Cullen, T. J. Toops, G. Bender, B. S. Pivovar, J. B. Green Jr, and F.-Y. Zhang, J Mater Chem A, 5, 18469 (2017).

16. J. Mo, Z. Kang, S. T. Retterer, D. A. Cullen, T. J. Toops, J. B. Green, M. M. Mench, and F.-Y. Zhang, Science Advances, 2 (2016).

17. Z. Kang, G. Yang, J. Mo, S. Yu, D. A. Cullen, S. T. Retterer, T. J. Toops, M. P. Brady, G. Bender, B. S. Pivovar, J. B. Green, and F.-Y. Zhang, International Journal of Hydrogen Energy, 43, 14618 (2018).

18. S. A. Grigoriev, P. Millet, S. A. Volobuev, and V. N. Fateev, International Journal of Hydrogen Energy, 34, 4968 (2009).

19. T. Schuler, R. De Bruycker, T. J. Schmidt, and F. N. Büchi, Journal of The Electrochemical Society, 166, F270 (2019).

20. M. Suermann, A. Pătru, T. J. Schmidt, and F. N. Büchi, International Journal of Hydrogen Energy, 42, 12076 (2017).

21. R. B. Belser and W. H. Hicklin, J Appl Phys, 30, 313 (1959).

22. H. Ito, T. Maeda, A. Nakano, and H. Takenaka, International Journal of Hydrogen Energy, 36, 10527 (2011).

23. T. A. Greszler, D. Caulk, and P. Sinha, Journal of the Electrochemical Society, 159 (2012).

24. T. Schuler, A. Chowdhury, A. T. Freiberg, B. Sneed, F. B. Spingler, M. C. Tucker, K. L. More, C. J. Radke, and A. Z. Weber, Journal of The Electrochemical Society, 166, F3020 (2019)

25. S. M. Alia, K. E. Hurst, S. S. Kocha, and B. S. Pivovar, Journal of The Electrochemical Society, 163, F3051 (2016)

26. R. W. Kopitzke, C. A. Linkous, H. R. Anderson, and G. L. Nelson, Journal of the Electrochemical Society, 147, 1677 (2000).

27. T. A. Zawodzinski, C. Derouin, S. Radzinski, R. J. Sherman, V. T. Smith, T. E. Springer, and S. Gottesfeld, Journal of The Electrochemical Society, 140, 1041 (1993).

28. J. D. P. Peter and W. Atkins, Atkins' Physical Chemistry, Wiley-VCH (2013).

29. A. Fallisch, L. Schellhase, J. Fresko, M. Zechmeister, M. Zedda, J. Ohlmann, L. Zielke, N. Paust, and T. Smolinka, International Journal of Hydrogen Energy, 42, 13544 (2017).

30. D. L. Fritz, J. Mergel, and D. Stolten, Ecs Transactions, 58, 1 (2014). 
31. C. Immerz, M. Paidar, G. Papakonstantinou, B. Bensmann, T. Bystron, T. Vidakovic-Koch, K. Bouzek, K. Sundmacher, and R. Hanke-Rauschenbach, Journal of Applied Electrochemistry, 48, 701 (2018).

32. A. Kusoglu and A. Z. Weber, Chemical Reviews, 117, 987 (2017).

33. J. T. Hinatsu, M. Mizuhata, and H. Takenaka, Journal of The Electrochemical Society, 141, 1493 (1994).

34. F. N. Büchi, B. Gupta, O. Haas, and G. G. Scherer, Electrochim Acta, 40, 345 (1995)

35. T. Sakai, H. Takenaka, N. Wakabayashi, Y. Kawami, and E. Torikai, Journal of The Electrochemical Society, 132, 1328 (1985).

36. M. Bernt and H. A. Gasteiger, Journal of The Electrochemical Society, 163, F3179 (2016)

37. H. Ito, T. Maeda, A. Nakano, C. M. Hwang, M. Ishida, A. Kato, and T. Yoshida, International Journal of Hydrogen Energy, 37, 7418 (2012).

38. F. B. Spingler, A. Phillips, T. Schuler, M. C. Tucker, and A. Z. Weber, International Journal of Hydrogen Energy, 42, 13960 (2017).

39. J. P. Owejan, J. E. Owejan, and W. B. Gu, Journal of the Electrochemical Society, 160, F824 (2013)

40. A. Orfanidi, P. Madkikar, H. A. El-Sayed, G. S. Harzer, T. Kratky, and H. A. Gasteiger, Journal of The Electrochemical Society, 164, F418 (2017).
41. A. Z. Weber and A. Kusoglu, J Mater Chem A, 2, 17207 (2014)

42. S. Shukla, D. Stanier, M. S. Saha, J. Stumper, and M. Secanell, Journal of the Electrochemical Society, 163, F677 (2016).

43. K. Onda, T. Murakami, T. Hikosaka, M. Kobayashi, R. Notu, and K. Ito, Journal of The Electrochemical Society, 149, A1069 (2002).

44. C. Immerz, M. Schweins, P. Trinke, B. Bensmann, M. Paidar, T. Bystroň, K. Bouzek, and R. Hanke-Rauschenbach, Electrochim Acta, 260, 582 (2018).

45. A. C. Olesen, S. H. Frensch, and S. K. Kær, Electrochim Acta, 293, 476 (2019).

46. B. Verdin, F. Fouda-Onana, S. Germe, G. Serre, P. A. Jacques, and P. Millet, International Journal of Hydrogen Energy, 42, 25848 (2017).

47. N. E. De Almeida, D. K. Paul, K. Karan, and G. R. Goward, The Journal of Physical Chemistry C, 119, 1280 (2015).

48. Z. Siroma, R. Kakitsubo, N. Fujiwara, T. Ioroi, S.-I. Yamazaki, and K. Yasuda, $J$ Power Sources, 189, 994 (2009).

49. D. R. P. Morris, S. P. Liu, D. Villegas Gonzalez, and J. T. Gostick, ACS Applied Materials \& Interfaces, 6, 18609 (2014).

50. A. Kusoglu, D. Kushner, D. K. Paul, K. Karan, M. A. Hickner, and A. Z. Weber, Advanced Functional Materials, 24, 4763 (2014) 